\title{
Recurrence of Seizure after Antiepileptic Drug Withdrawal in Children with Epilepsy
}

\author{
Mizanur Rahman ${ }^{1}$, Sufia Khatun Sumi ${ }^{2}$ and Kanij Fatema ${ }^{3 *}$ \\ ${ }^{1}$ Department of Pediatric Neurology, Bangabandhu Sheikh Mujib Medical University, Bangladesh \\ ${ }^{2}$ Department of Pediatric Neurology, National Institute of Neurosciences, Bangladesh \\ ${ }^{3}$ Department of Pediatric Neurology, Bangabandhu Sheikh Mujib Medical University, Bangladesh
}

Submission: January 02, 2019; Published: February 26, 2019

*Corresponding author: Kanij Fatema, FCPS, Department of Pediatric Neurology, Bangabandhu Sheikh Mujib Medical University, Dhaka, Bangladesh

\section{Abstract}

Background: Withdrawal of antiepileptic drug (AED) should be considered after a reasonable seizure free period despite the risk of seizure recurrence in epileptic patients. This study was done to determine the factors associated with seizure recurrence after antiepileptic drug withdrawal among children with remission of seizure for 2 years or more.

Methods: This was a retrospective study done from February 2012 to March 2017. The medical records of the cases were analyzed. Children with epilepsy with age of onset of seizure less than 15 years were followed up at least 1 year after withdrawal of AED at a child neurology center. The patients were divided into 'Seizure Recurrence (SR) group' and 'Non-Seizure Recurrence (NSR) group' based on the outcome after stopping medications. For the comparison of clinical findings, electroencephalograms and parameters related to treatment, univariate and multivariate analyses were done.

Results: Total 100 patients (62 boys, 38 girls) were analysed. Among them recurrence rate was 38\%. Most of the recurrences occurred within first five months of withdrawal of AED. Factors highly associated with SR were high seizure frequency, history of status epilepticus, cognitive impairment, abnormal EEG when AED was stopped, rapid withdrawal of AED and seizure free period before tapering of AED.

Conclusion: This study revealed that initial high frequency of seizure, abnormal EEG when AED stopped are important predictors of SR in children with epilepsy.

Keywords: Antiepileptic drug; Seizure recurrence; Non-seizure recurrence; Seizure recurrence; Epilepticus; Medication; Epilepsy; Brain; Polytherapy

Abbreviations: SR: Seizure Recurrence; AED: Antiepileptic Drugs; NSR: Non-Seizure Recurrence

\section{Introduction}

In children with epilepsy, the critical question of discontinuation of Antiepileptic Drugs (AED) arises after a seizure free period despite the risk of seizure recurrence [1-5]. Early withdrawal of AED is not recommended as a standard practice in children, even in those who rapidly respond to medication. However, many physician believe that, it is necessary to stop medication after 2 years [6-8]. Approximately 70\% epileptic children who are seizure free for more than 2-4 years while on AEDs remain seizure free after discontinuation of drug $[6,9,10]$. Numerous studies discuss about the possible risk factors which may influence seizure recurrence following discontinuation [11]. As AED has long term adverse effect together with psychosocial and economic burden, it is necessary to identify the predictors of seizure recurrence after withdrawal of drugs [12]. In this study, an attempt was made to determine the risk factors associated with seizure recurrence after a seizure free period of 2 years.

\section{Methodology}

This study was conducted in the Department of Pediatric Neurology in Bangabandhu Sheikh Mujib Medical University, Dhaka, Bangladesh among children with epilepsy whose AED were withdrawn after 2-year seizure free period and followed up at least 1 year after discontinuation of drug. This study was done between March 2012 to February 2017. The children who received AED since March 2009 were included. The inclusion criteria were as follows onset of epilepsy before 15 years of age, established clinical remission of at least two years before 


\section{Open Access Journal of Neurology \& Neurosurgery}

AED withdrawal and clinical follow up for at least one year after withdrawal. Informed written consent was taken from all parents. Relevant clinical information was obtained retrospectively from the medical records in a structured data collection sheet. Parents were interviewed by telephone to determine if seizure recurred in the long term follow up in March 2018. Children were not eligible for the study if parents were unreachable, all needed relevant data were not available from the case history notes and who dropped out of the follow up for different reasons. If there was recurrence of seizure, AED was restarted at the previous dose. Based on the outcome after stopping the medication, the

\section{Patients were divided into two groups}

a. SR group (Seizure recurrence during the 1 year follow up), and

b. NSR group (no seizure recurrence during the 1-year follow-up).

The information on each patient recorded were age, sex, age at seizure onset, perinatal and developmental history, family history of epilepsy, history of complex febrile seizure, status epilepticus, seizure types, localization related seizure, initial seizure frequency, presence of abnormal neurological findings, etiology of epilepsy, time period between the onset of first seizure and start of AED treatment, treatment response time, total number of AED before remission, first EEG and neuroimaging findings. EEG before withdrawal of AED was also recorded. Seizures were classified according to the 1989 classification of the International League against Epilepsy. Cognitive impairment was estimated based on the clinical estimation and psychological assessment was also administered when indicated.

SPSS statistical analysis software package version 19.5 (SPSS Inc., Chicago, IL) was used in the statistical analysis. Statistical significance was accepted at $\mathrm{P}<0.05$. The Chi-square tests were used to determine the associations between categorical data. We carried out univariate and multivariable analyses of potential predictors of recurrence risk using Cox regression analysis.

\section{Results}

A total of 123 patients were identified according to inclusion criteria. Among them, 13 patients were unreachable and 10 had poor medical documentation. The remaining 100 patients of initial seizure remission were enrolled in the study. Sixty two percent remained seizure free (NSR group) and 38\% had recurrence of seizure (SR group). Boys were more likely to have SR than girls. More than half of the patient of SR group had age of onset $<2$ years. Perinatal insult was found in 33\% children \& $30 \%$ had developmental delay. It was found that $6 \%, 7 \%$ and $18 \%$ patients had history febrile seizure, family history of epilepsy and status epilepticus respectively. Regarding seizure type, $47 \%$ had partial epilepsy and $53 \%$ had generalized epilepsy. Cognitive impairment was found in 30 children both at the start and during the course of treatment which were significant in SR group in comparison to NSR group. Most relapses occurred within 5 months after withdrawal of AED. Initial seizure frequency ( $>1$ in every month) was significantly higher for the children with seizure recurrence than for those without (Table 1).

Table 1: Comparison of clinical characteristics of children in seizure recurrence (SR) and no seizure recurrence (NSR) group.

\begin{tabular}{|c|c|c|c|}
\hline Parameters & SR $(n=38)$ No. $(\%)$ & NSR (n= 62) No.\%) & P Value \\
\hline \multicolumn{4}{|c|}{ Sex } \\
\hline Male & $26(68.4)$ & $36(58 \%)$ & 0.3 \\
\hline Female & $12(31.6)$ & $26(41.9 \%)$ & \\
\hline \multicolumn{4}{|c|}{ Age of Onset (Years) } \\
\hline$<2$ & $20(52.6)$ & $22(35.5)$ & 0.877 \\
\hline $2-5$ & $10(26.3)$ & $11(17.7)$ & 1 \\
\hline$>5$ & $8(21.1)$ & $29(46.8)$ & $0.001^{*}$ \\
\hline Perinatal insult & $16(42.1)$ & $17(27.4)$ & 0.13 \\
\hline Developmental delay & $16(42.1)$ & $14(22.6)$ & $0.039 *$ \\
\hline Family history of seizure & $2(5.3)$ & $5(8.1)$ & 0.594 \\
\hline History of complex febrile seizure & $3(7.9)$ & $3(4.8)$ & 0.532 \\
\hline \multicolumn{4}{|c|}{ Localization Related Seizure } \\
\hline Generalized & $20(52.6)$ & $33(53.2)$ & 0.954 \\
\hline Partial & $18(47.4)$ & $29(46.8)$ & \\
\hline History of status epilepticus & 7 (18.4) & $11(17.7)$ & 0.932 \\
\hline \multicolumn{4}{|c|}{ Initial Seizure Frequency } \\
\hline High (> 1 every month) & $26(68.4)$ & $12(19.4)$ & $0.035^{*}$ \\
\hline Mod (1-2 every 1-3 month) & $4(10.5)$ & $11(17.7)$ & 0.118 \\
\hline
\end{tabular}




\section{Open Access Journal of Neurology \& Neurosurgery}

\begin{tabular}{|c|c|c|c|}
\hline Low & $8(21.1)$ & $39(62.9)$ & $0.0001^{*}$ \\
\hline Cognitive impairment & $18(47.4)$ & $12(19.4)$ & $0.003^{*}$ \\
\hline
\end{tabular}

SR: Seizure Recurrence; NSR: Non-Seizure Recurrence; Chi- Square test*: Significant at $\mathrm{P}<0.05$

EEG was found abnormal in $76.3 \%$ of the SR group and $77.4 \%$ in NSR group. Pre-withdrawal EEG was abnormal in $10 \%$ patients before starting tapering of AED (18.4\% in the SR group and $4.8 \%$ in the NSR group) (Table 2). CT scan of brain was found abnormal in $18.4 \%$ and $16.1 \%$ patients in SR and NSR group respectively which mostly revealed cerebral atrophy and infarction.

The seizure free period was significantly shorter $\{<3$ years) in patients with SR than patients without recurrence $(p=0.0001)$. Patient with SR had also shorter duration of withdrawal/ tapering of drug than NSR group $(p=0.0001)$. The percentage of patients requiring polytherapy was higher in SR group (65.8\%) than NSR group (48.4\%) although not statistically significant (Table $2 \& 3$ ) The most important predictors of seizure recurrence were high seizure frequency, history of status epilepticus, cognitive impairment, abnormal EEG when AED stopped, rapid withdrawal of AED and seizure free period before tapering of AED.

Table 2: Comparison of electroencephalographic and treatment related parameters of children in SR and NSR group.

\begin{tabular}{|c|c|c|c|}
\hline Parameters & SR $(n=38)$ No. $(\%)$ & NSR $(n=62)$ No. (\%) & P Value \\
\hline $\begin{array}{l}\text { EEG abnormality when epilepsy } \\
\text { was diagnosed }\end{array}$ & $29(76.3)$ & $48(77.4)$ & $0.040^{*}$ \\
\hline $\begin{array}{l}\text { Pre-withdrawal EEG abnormality } \\
\text { before starting tapering of AED }\end{array}$ & $7(18.4)$ & $3(4.8)$ & $0.028^{*}$ \\
\hline CT scan abnormality & $7(18.4 \%)$ & $10(16.1 \%)$ & 0.629 \\
\hline \multicolumn{4}{|c|}{ Time Between Onset of $1 \mathrm{st}$ Seizure and Initiation of Treatment } \\
\hline $0-2$ month & $34(89.5)$ & $58(93.5)$ & $0.016^{*}$ \\
\hline $2-12$ months & $2(5.3)$ & $2(3.2)$ & 1 \\
\hline$>12$ months & $2(5.3)$ & $2(3.2)$ & 1 \\
\hline \multicolumn{4}{|c|}{ Treatment Response Time } \\
\hline $0-2$ month & $14(36.8)$ & $36(58.1)$ & $0.003^{*}$ \\
\hline 2-12 months & $19(50)$ & $21(33.9)$ & 0.874 \\
\hline$>12$ months & $5(13.2)$ & $5(8.1)$ & 1 \\
\hline \multicolumn{4}{|c|}{ Seizure Free Period Before Tapering Of AED } \\
\hline$<3$ years & $23(60.5)$ & $6(9.7)$ & $0.0001^{*}$ \\
\hline$>=3$ years & $15(39.5)$ & $56(90.3)$ & \\
\hline \multicolumn{4}{|c|}{ Total Duration of Withdrawal of Drug } \\
\hline 1-6 months & $23(60.5)$ & $7(11.3)$ & $0.0001^{*}$ \\
\hline$>6$ months & $15(39.5)$ & $55(88.7)$ & \\
\hline \multicolumn{4}{|c|}{ AED Treatment Before Remission } \\
\hline Monotherapy & $13(34.2)$ & $32(61.6)$ & 0.09 \\
\hline Polytherapy & $25(65.8)$ & $30(48.4)$ & \\
\hline
\end{tabular}

Table 3: Risk factors for seizure recurrence in children after stopping AED.

\begin{tabular}{|c|c|c|c|}
\hline Risk Factors & Hazard Ratio & $95 \%$ Confidence Interval & P Value \\
\hline Early onset epilepsy & 0.81 & $0.37-1.77$ & 0.593 \\
\hline History of status epilepticus & $1.03^{*}$ & $0.41-2.58$ & 0.952 \\
\hline Initial high seizure frequency & $1.51^{*}$ & $0.69-3.31$ & 0.304 \\
\hline Seizure type (Partial with generalized) & 0.8 & $0.33-1.94$ & 0.628 \\
\hline Abnormal EEG when AED stopped & $1.50^{*}$ & $0.64-3.52$ & 0.352 \\
\hline Cognitive impairment & 1 & $0.46-2.17$ & 0.989 \\
\hline Sudden/ rapid withdrawal of AED & $1.15^{*}$ & $0.50-2.64$ & 0.742 \\
\hline Seizure free period before tapering of AED & $2.30^{*}$ & $0.94-5.60$ & 0.068 \\
\hline
\end{tabular}




\section{Discussion}

In this study the recurrence after discontinuation of AED therapy was $38 \%$, which is consistent with the most of other studies which showed approximately $70-80 \%$ of children remained seizure free after withdrawal of drug [1-16]. Recurrence occurred mostly in the first 5 months as reported previously $[1,2,15,16]$. Here male gender was more likely to have SR than female, although some studies found female gender as a significant risk factor for relapse [1,17]. In most of the studies it was observed that gender had no influence on relapse risk. This discrepancy may result from the differences in the study population and study design [2-5,15-18]. Age at onset of seizure is a predictive factor which is considered by many authors although it is controversial. Some study found younger age at onset as a good prognostic factor where epileptic syndrome with bad prognosis were excluded $[1,6]$. Few studies reported age of onset more than 12 years as a risk factor for recurrence whereas others did not find any influence of age of onset on SR $[15,16,18]$. In this study younger age of onset was found to be correlated with a risk of SR after stopping AED which was consistent with another study [12]. Many children of less than 2 years (52.6\%) were in SR group, but in multivariate analysis it didn't show as significant risk factor. This may be due to the fact that children with younger age of onset were most likely to have symptomatic epilepsy who had perinatal insult and developmental delay.

Some studies showed family history as a risk factor for SR, but it was not found in this study, which is also consistent with some other studies. History of febrile convulsion was also not shown as a risk factor which also supports the results of other studies $[1,2,19]$. Cognitive impairment of varying degree can be related to $\mathrm{SR}[2,5,13,17,18,20]$, and this is also found in this study. This may be due to the fact that most of the patients had perinatal insult, initial high seizure frequency and got polytherapy. In this study $47.4 \%$ children who had SR had cognitive delay in comparison to NSR group (19.4\%).

There was no significant difference in relation to seizure type which has similarity with study done by Olmez et al. [12] although some other studies showed seizure type as a risk factor $[18,21]$. The variation regarding the seizure type can be attributed to differences in study design and characteristics of study population. Some study reported that after discontinuing drugs, the risk for seizure recurrence included status epilepticus, EEG abnormality when AED were stopped and symptomatic epilepsy $[12,15]$. In this study, the ratio of status epilepticus in seizure recurrence group was greater than in non-SR group, but it was not significant, probably because of small number of cases. When cox hazard function test was done, higher initial seizure frequency, history of status epilepticus as well as EEG abnormality at the time of stopping AED were found as risk factors.
Time between onset of first seizure and onset of AED treatment as well as polytherapy was reported as a risk factor of SR in few studies [16,19-22]. In this study it was also found Thant minimum time between first seizure and starting of AED, treatment response time and seizure free period before tapering AED were also statistically significant. There was significant difference between the groups of patients with AED tapering more than 6 months versus less than 6 months which was consistent with another study and considered as a risk factor, whereas few other studies did not find any difference regarding the tapering period of AED [18, 19-22].

\section{Conclusion}

The recurrence rate of this study was almost similar to most of the other studies. Initial high seizure frequency, history of status epilepticus, abnormal EEG when AED stopped, rapid withdrawal of AED and seizure free period before tapering of AED were important predictors of SR in childhood epilepsy.

\section{Limitation}

This was a single center study, which might lead to selection bias. The sample size was small. Thus, statistical findings were not very strong. This was also a retrospective study from medical records, so some data might be missing which could add valuable information to identify the risk factors of seizure recurrence.

\section{References}

1. Altunbașak S, Artar O, Burgut R, Yildiztaş D (1999) Relapse risk analysis after drug withdrawal in epileptic children with uncomplicated seizures. Seizure 8(7): 384-389.

2. Bouma PA, Peters AC, Arts RJ, Stijnen T, Van RJ (1987) Discontinuation of antiepileptic therapy: a prospective study in children. J Neurol Neurosurg Psychiatry 50(12): 1579-1583.

3. Serra JG, Montenegro MA, Guerreiro MM (2005) Antiepileptic drug withdrawal in childhood: does the duration of tapering off matter for seizure recurrence? J Child Neurol 20(7): 624-626.

4. Bouma PA, Peters AC, Brouwer OF (2002) Long term course of childhood epilepsy following relapse after antiepileptic drug withdrawal. J Neurol Neurosurg Psychiatry 72(4): 507-510.

5. Shinnar S, BergAT, MosheSL, Kang H, O Dell C, etal. (1994) Discontinuing antiepileptic drugs in children with epilepsy: a prospective study. Ann Neurol 35(5): 534-545.

6. Shinnar S, Vining EP, Mellits ED, D Souza BJ, Holden K, et al. (1985) Discontinuing antiepileptic medication in children with epilepsy after two years without seizures. A prospective study. N Engl J Med 313(16): 976-980.

7. Verrotti A, Morresi S, Basciani F, Cutarella R, Morgese G, et al. (2000) Discontinuation of anticonvulsant therapy in children with partial epilepsy. Neurology 55(9):1393-1395.

8. Li W, Si Y, Zou XM, An DM, Yang H, et al. (2014) Prospective study on the withdrawal and reinstitution of antiepileptic drugs among seizure-free patients in west China. J Clin Neurosci 21(6): 997-1001.

9. Arts WF, Visser LH, Loonen MC, Tjiam AT, Stroink H, et al. (1988) Followup of 146 children with epilepsy after withdrawal of antiepileptic therapy. Epilepsia 29(3): 244-250. 
10. Camfield PR, Camfield CS (1996) Antiepileptic drug therapy: when is epilepsy truly intractable? Epilepsia 37(1): S60-65.

11.S Kilınc, C Campbell (2008) The experience of discontinuing antiepileptic drug treatment: An exploratory investigation. Seizure 17(6): 505-513.

12. Olmez A, Arslan U, Turanli G, Aysun S (2009) Risk of recurrence after drug withdrawal in childhood epilepsy. Seizure 18(4): 251-256.

13. Arts WF, Brouwer OF, Peters AC, Stroink H, Peeters EA, et al. (2004) Course and prognosis of childhood epilepsy: 5-year follow-up of the Dutch study of epilepsy in childhood. Brain 127(8): 1774-1784.

14. Wallis WE (1987) Withdrawal of anticonvulsant drugs in seizure-free epileptic patients. Clin Neuro pharmacol 10: 423-433.

15. Berg AT, Shinnar S (1994) Relapse following discontinuation of antiepileptic drugs: a meta-analysis. Neurology 44(4): 601-608.

16. Gherpelli JL, Kok F, dal Forno S, Elkis LC, Lefevre BH, et al. (1992) Discontinuing medication in epileptic children: a study of risk factors related to recurrence. Epilepsia 33(4): 681-686.
17. Dooley J, Gordon K, Camfield P, Camfield C, Smith E (1996) Discontinuation of anticonvulsant therapy in children free of seizures for 1 year: a prospective study. Neurology 46(6): 969-974.

18. Todt $H$ (1984) The late prognosis of epilepsy in childhood: results of a prospective follow-up study. Epilepsia 25(2): 137-144.

19. Verrotti A, Morresi S, Cutarella R, Morgese G, Chiarelli F (1999) Factors associated with relapse after antiepileptic drug withdrawal in a selected population with partial epilepsy. Dev Med Child Neurol 41(9): 643-645.

20. Matricardi M, Brinciotti M, Benedetti P (1989) Outcome after discontinuation of antiepileptic drug therapy in children with epilepsy. Epilepsia 30(5): 582-589.

21. Specchio LM, Tramacere L, La Neve A, Beghi E (2002) Discontinuing antiepileptic drug in patients who are seizure free on monotherapy. J Neurol Neurosurg Psychiatry 72(1): 22-25.

22. Ohta H, Ohtsuka Y, Tsuda T, Oka E (2004) Prognosis after withdrawal of antiepileptic drugs in childhood-onset cryptogenic localization related epilepsies. Brain Dev 26(1): 19-25.

\section{Your next submission with Juniper Publishers} will reach you the below assets

- Quality Editorial service

- Swift Peer Review

- Reprints availability

- E-prints Service

- Manuscript Podcast for convenient understanding

- Global attainment for your research

- Manuscript accessibility in different formats

( Pdf, E-pub, Full Text, Audio)

- Unceasing customer service

Track the below URL for one-step submission https://juniperpublishers.com/online-submission.php 